\title{
Yellow rust races found in 2018-19 collection from wheat growing areas of Pakistan
}

Muhammad Sufyan ${ }^{1}$, Javed Iqbal Mirza ${ }^{1}$, Muhammad Saeed ${ }^{2 *}$, Muhammad Fayyaz, Khalil Ahmad Khanzada ${ }^{4}$, Atiq ur Rehman Rattu ${ }^{5}$ and Muhammad Qasim Kakar ${ }^{6}$

1. Crop Diseases Research Institute, PARC Substation Murree-Pakistan

2. Wheat Research Sub-Station Murree-Pakistan

3. Crop Diseases Research Institute, NARC Islamabad-Pakistan

4. Crop Diseases Research Institute, PARC University of Karachi-Pakistan

5. National Coordinator Wheat, PARC Islamabad-Pakistan

6. Agriculture Research Institute, Quetta-Pakistan

*Corresponding author's email: saeedkalvi114@gmail.com

Citation

Muhammad Sufyan, Javed Iqbal Mirza, Muhammad Saeed, Muhammad Fayyaz, Khalil Ahmad Khanzada, Atiq ur Rehman Rattu and Muhammad Qasim Kakar. Yellow rust races found in 2018-19 collection from wheat growing areas of Pakistan. Pure and Applied Biology. Vol. 10, Issue 4, pp1063-1069.

http://dx.doi.org/10.19045/bspab.2021.100110

Received: $13 / 11 / 2020$

Revised: $31 / 12 / 2020$

Accepted: 05/01/2021

Online First: 08/01/2021

\section{Abstract}

Wheat (Triticum aestivum) as staple food ensures around 20\% global calories of human consumption. Yellow rust (Yr) pathogen Puccinia striiformis f. sp. tritici (PST) significantly reduced wheat production. The current study was conducted to identify the stripe rust virulence pattern and the prevalence of the most dominant stripe rust races in 2018-19. The virulence analysis identified 8 PST races from analyzed samples, and amongst these races, 564200 was the most frequent race, followed by 574201 and 574200. The rest of the races, including 574210, 564202, 560200,574232 and 164200 , constituted $6.66 \%$ of all the identified races. No virulence was found for Yr5, Yr10, Yr15, Yr24, Yr32, YrSp and YrTye whereas, all the isolated races/pathotypes were found virulent to genes including Yr1, Yr8, Yr9 and Yr27. The genes Yr6 and Yr17 were found susceptible against all races except race 164200 and 560200, respectively. Race 574210 found virulent to Yr43, while 574232 found virulent to Yr42 and Yr43. Yr genes avirulence/virulence information can be utilized in gene deployment and breeding programs in Pakistan.

Keywords: Races; Wheat; Yellow rust

\section{Introduction}

Wheat (Triticum aestivum) holds the key position as a major acreage crop worldwide with approximately 220 million hectares' area and 760 million tons' production in 2018. After maize, wheat ranked 2 nd in production globally [1]. Wheat as staple food also ensures around $20 \%$ global calories of human consumption [2]. As in the next three decades, the population is likely to be increased up to two billion people globally and ultimately also increased the demand for wheat [3]. Yellow rust (Yr) significantly reduced wheat production under disease 
favorable conditions [4] in key wheatproducing countries including China, Canada, Australia, Pakistan, India, France and United States $[5,6]$. Worldwide around 5.5 million tons of yield losses have been estimated every year [7]. In the past few decades' stripe rust outbreaks at the regional level have been reported worldwide. In North Africa, predominantly in Morocco from 2009 to onward, high disease pressure was observed [8]. In Central Asian countries, stripe rust epidemics were observed in Tajikistan in 2010, followed by Uzbekistan [9]. Similarly, during 2010 stipe rust was also detected in Lebanon and Syria resulting in economic losses [10]. Winds plays an essential role in long-distance dispersal of the stripe rust fungus, as reported among England and Denmark [11], whereas the polycyclic nature of disease also favors the spread of field to filed migration [12]. Accidentally, humans have also become a source to spread the disease between continents by carrying pathogens with goods or clothes as in 1979 PST introduced in Australia from Europe [13]. Although pathogen has the ability of long-distance dispersal, but the migration amongst countries is contemporary as predominant emergences reported in the past few decades. In 1996 pathogen reported from South Africa and the detected pathotypes were the same as present in Mediterranean regions and the Middle East [14]. Similarly, in the 20th century, PST reported the first time from South America with an unknown source [15]. Meanwhile, with the expansion of geographical areas PST is now also emerging in warm climatic conditions as documented from south eastern USA [16]. Subsequently, the same high temperature adaptive aggressive genotype was reported from Australia after two years and another closely linked genotype was observed in East Africa, Central and West Asia and Europe [14, 17]. Most pathotypes are emerging from some unknown geographic origins. Virulent pathotypes to resistance gene $\mathrm{Yr}$ 9 were first reported in 1986 from Ethiopia (Eastern Africa) and later on from the Middle East, Pakistan, India and reached up to Bangladesh within 12 years [18]. To overcome the spread and load of rusts, sowing resistant wheat varieties/cultivars is the most sustainable and environment-friendly way. 13 PST epidemics have been documented in Pakistan since 1948 [19]. As compared to the Central and Western areas, the disease frequency was more in the Northern regions of the country, as the environment favors the PST becoming a serious issue to southern Punjab and Province Sindh [20]. The emergence of more virulent and aggressive races/pathotypes required regular monitoring to control the country's rust situation. To combat with emerging aggressive races of PST new sources of resistance need to be explored. The current research work was designed to find out the diversity of PST in Pakistan and to identify the most prevalent races in the culture collection.

\section{Materials and Methods Sampling}

Wheat leaves infected with stripe rust disease were collected from different wheat growing area of Pakistan and were processed at Crop Diseases Research Institute Sub-Station Sunny Bank Murree (CDRI-Murree). Number of PST samples received at CDRIMurree were dependent on disease situation and surveillance effort. Diseased samples were along with surveillance data consisting of information about, GPS location/city, province, field (Farmer field/experimental field/roadside), Growth stage (booting, tillering, milk, dough, mature), Disease type (Yr, Lr, Sr), disease incidence, disease severity and variety name were received at CDRI Labs. Fifteen of the received samples were processed which include 07 from Punjab, 05 from Khyber Pakhtunkhwa and 03 from Sindh. 


\section{Revival and isolation}

The infected leaves received at CDRI Labs were washed under running tap water and plated in petri dishes lined with filter paper. The plated samples were kept at $13^{\circ} \mathrm{C}$ under humid conditions for 12 hours. Spores form the plated disease samples were then inoculated on 8-10 days old susceptible Morocco plants. Plants were misted with water before inoculation and urediniospores were taken from the samples were rubbed against the abaxial surface the morocco leaves. The inoculated plants were then incubated in dark at $15^{\circ} \mathrm{C}$ for $18 \mathrm{~h}$ under $100 \%$ relative humidity. Afterward these plants were shifted to clean chamber of glasshouse maintained at $17^{\circ} \mathrm{C}$ day, $12^{\circ} \mathrm{C}$ night temperature and $16 \mathrm{~h}$ photo-period of daylight and $8 \mathrm{~h}$ dark. To avoid contamination amongst stripe rust spores the inoculated plants were covered with cellophane bags soon after moving to glasshouse. After 15-20 days when sporulating lesions started producing spores inoculum was collected from them by dusting them on butter paper.

\section{Race analysis}

Avirulence/virulence analysis of stripe rust was carried out on set of 18 yellow rust differential lines including Yr1, Yr5, Yr6, Yr7, Yr8, Yr9, Yr10, Yr15, Yr17, Yr24, Yr27, Yr32, Yr43, Yr44, Yr Spalding Prolific (Sp), YrTr1, Yr Exp2 and Yr Tye. Lines with Yr2, Yr4b/H46, Yr25, Yr28, Yr31 and YrA were also included as supplementary set. Differential lines were inoculated by following standard inoculation protocols developed and adapted at CDRI Murree Labs using a mixture of mineral oil and petroleum sprit as a carrier. Data was recorded on 0-9 scale where infection type 0-6 reflected resistance (R) and 7-9 shows complete susceptibility (S). If any individual gene line exhibited multiple infection types, single spore culture was developed to analyzed the sample [21, 22].

\section{Results and Discussion}

Race/virulence analysis identified 8 races (Table 1). Race 564200 was the most prevalent race, which constituted $40 \%$ of the total analyzed samples. Races 574200 and 574201 constituted $26 \%$ of the samples and differed from the 564200 in having virulence to Yr7. Whereas Race 574201 differed from the 574200 in being virulent to YrTr1. The rest of the races, including 574210, 564202, 560200, 574232 and 164200 (Fig. 1), constituted $6.66 \%$ of all the identified races. All the isolated races were virulent to genes including Yr1, Yr8, Yr9, and Yr27, whereas Yr6 showed susceptibility against all races except 164200. Similarly, Yr17 was only resistant to race 560200. Race 574232 was frequently encountered in 2014 and 2017 and isolated from commercial cultivars like inqilab-91, Bakkar, Sher-06 and Faisalabad08. The race can infect Yr1, Yr6, Yr7, Yr8, Yr9, Yr17, Yr27, Yr43, Yr44 and YrExp2 of which Yr1, Yr6, Yr9 and Yr27 were frequently found in old commercial cultivars. Race group 5742 is also significant as it shares virulence to Yr1, Yr6, Yr7, Yr8, Yr9, Yr24 and Yr27 with 574232. As most of the races share virulence's to these genes, the deployment of these should be avoided to avoid epidemic situations and recombination of these virulence with new ones. Race 564200 was virulent to Yr1, Yr6, Yr8, Yr9, Yr17 and Yr27 whereas race 574200 was virulent to Yr1, Yr6, Yr7, Yr8, Yr9, Yr17 and Yr27. Race 574201 found virulent to Yr1, Yr6, Yr7, Yr8, Yr9, Yr17, Yr27 and YrTr1. Race 574210 found virulent to Yr43, while race 574232 found virulent to $\mathrm{Yr} 42$ and Yr43. Race 574201 was found virulent to YrTr1 whereas, races 574332 and 564202 were virulent to YrExp2 (Table 1). Among supplementary set Yr4b/H46 was found resistant against all identified races in the current collection. The genes Yr2, Yr25, Yr31, Yr New Gains were susceptible against all identified races (Fig. 3). No virulence was 
found for Yr5, Yr10, Yr15, Yr24, Yr32, YrSp and YrTye in the analyzed samples (Fig. 2). Virulence to $\mathrm{Yr} 5 / \mathrm{Yr} 7 / \mathrm{YrSP}$ which cluster together and Yr15 was missing in our collection. These genes confer all stage resistance against PST, which is highly effective against specific PST races, but as PST evolves more aggressively against such resistance. A broad range of prevalent PST races found avirulent to Yr5 were also found avirulent to Yr15 [23], which conforms with our work as none of the races was found virulent to both genes. Virulence of Yr7, commonly found across the globe [24], was found in races 574210, 574200, 574201 and 574232. YrSp which confers a high level of resistance to PST races, is found rarely [24] was missing in our collection. In 2003-2004 mega wheat variety inqilab-91 carryingYr27 became susceptible which affected overall $80 \%$ of wheat growing area in the country [25]. Frequent virulence to Yr27 combined with other new virulence, found in our collection is probably due to the sexual recombination. Similarly, earlier in 1995, rust outbreaks on wheat varieties Pirsabak-85 and Pak-81 were documented due to the virulence to $\operatorname{Yr} 9[26,27]$ which is found in combination with Yr27. Virulence to Yr10 was also absent in the current collection, which is a dominant race-specific gene [28] an alternative allele reported from Triticum vavilovii [29]. In the past, [30] also reported the absence of its virulence in this region which confirmed current findings. Virulence of Yr17, which exists worldwide [31], and was found in all races identified except race 560200 .

Table 1. Avirulence/Virulence formula of stripe rust races identified

\begin{tabular}{|c|c|}
\hline Race & Avirulence/Virulence \\
\hline 564200 & $\begin{array}{l}\text { Yr5, Yr7, Yr10, Yr15, Yr24, Yr32, Yr43, Yr44, YrSp, YrTr1, YrExp2, YrTye/ Yr1, } \\
\text { Yr6, Yr8, Yr9, Yr17, Yr27 }\end{array}$ \\
\hline 574200 & $\begin{array}{l}\text { Yr5, Yr10, Yr15, Yr24, Yr32, Yr43, Yr44, YrSp, YrTr1, YrExp2, YrTye /Yr1, Yr6, } \\
\text { Yr7, Yr8, Yr9, Yr17, Yr27 }\end{array}$ \\
\hline 574201 & $\begin{array}{l}\text { Yr5, Yr10, Yr15, Yr24, Yr32, Yr43, Yr44, YrSp, YrExp2, YrTyel Yr1, Yr6, Yr7, } \\
\text { Yr8, Yr9, Yr17, Yr27, YrTr1 }\end{array}$ \\
\hline 574210 & $\begin{array}{l}\text { Yr5, Yr10, Yr15, Yr24, Yr32, Yr44, YrSp, YrTr1, YrExp2, YrTye /Yr1, Yr6, } \\
\text { Yr7,Yr8, Yr9, Yr17, Yr27, Yr43 }\end{array}$ \\
\hline 564202 & $\begin{array}{l}\text { Yr5, Yr7, Yr10, Yr15, Yr24, Yr32, Yr43, Yr44, YrSp, YrTr1, YrTyel Yr1, Yr6, Yr8, } \\
\text { Yr9, Yr17, Yr27, YrExp2 }\end{array}$ \\
\hline 560200 & $\begin{array}{l}\text { Yr5, Yr7, Yr10, Yr15, Yr17, Yr24, Yr32, Yr43, Yr44, YrSp, YrTr1, YrExp2, YrTyel } \\
\text { Yr1, Yr6, Yr8, Yr9, Yr27 }\end{array}$ \\
\hline 574232 & $\begin{array}{l}\text { Yr5, Yr10, Yr15, Yr24, Yr32, YrSp, YrTr1, YrTye / Yr1, Yr6, Yr7, Yr8, Yr9, Yr17, } \\
\text { Yr27, Yr43, Yr44, YrExp2 }\end{array}$ \\
\hline 164200 & $\begin{array}{l}\text { Yr5, Yr6, Yr7, Yr10, Yr15, Yr24, Yr32, Yr43, Yr44, YrSp, YrTr1, YrExp2, } \\
\text { YrTye/Yr1, Yr8, Yr9, Yr17, Yr27 }\end{array}$ \\
\hline
\end{tabular}




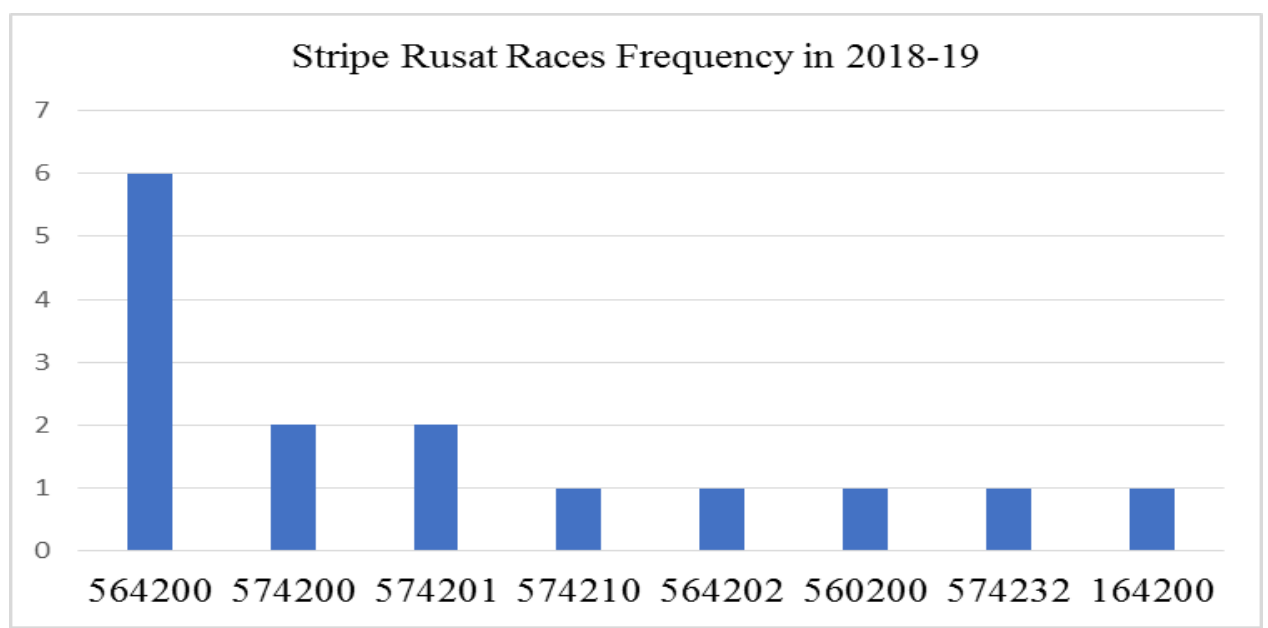

Figure 1. Frequency of stripe rust races collected from Pakistan

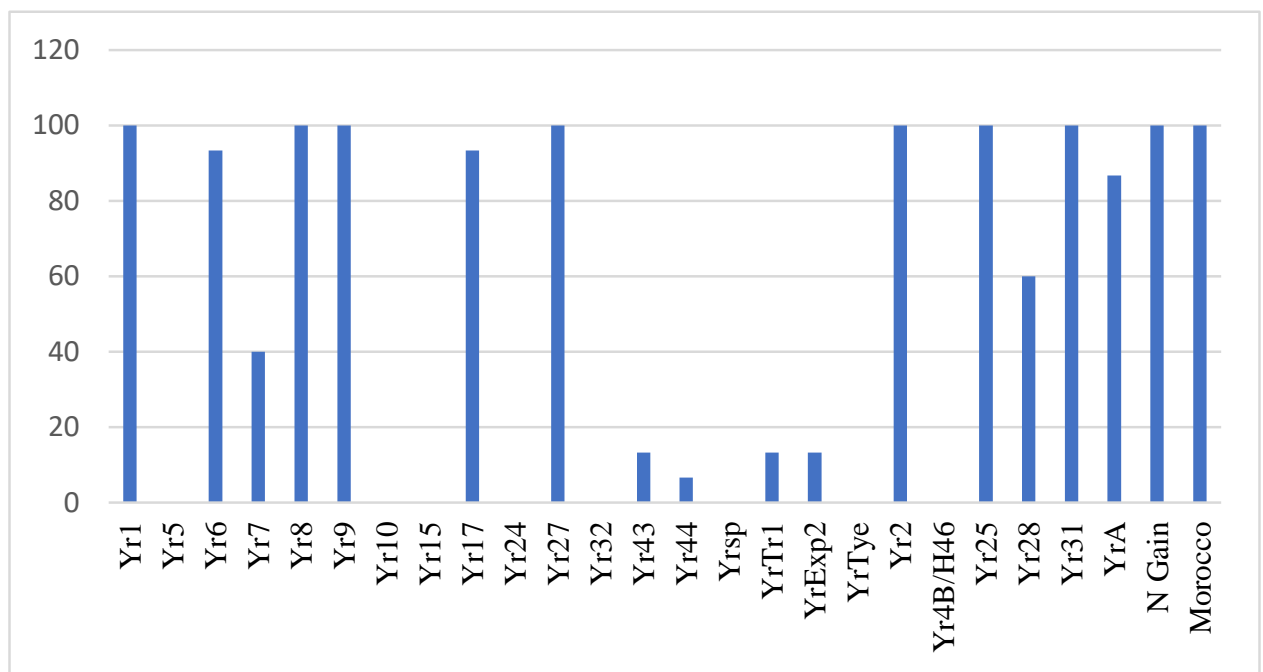

Figure 2. Virulence of stripe rust races against Yr genes (Differential set)

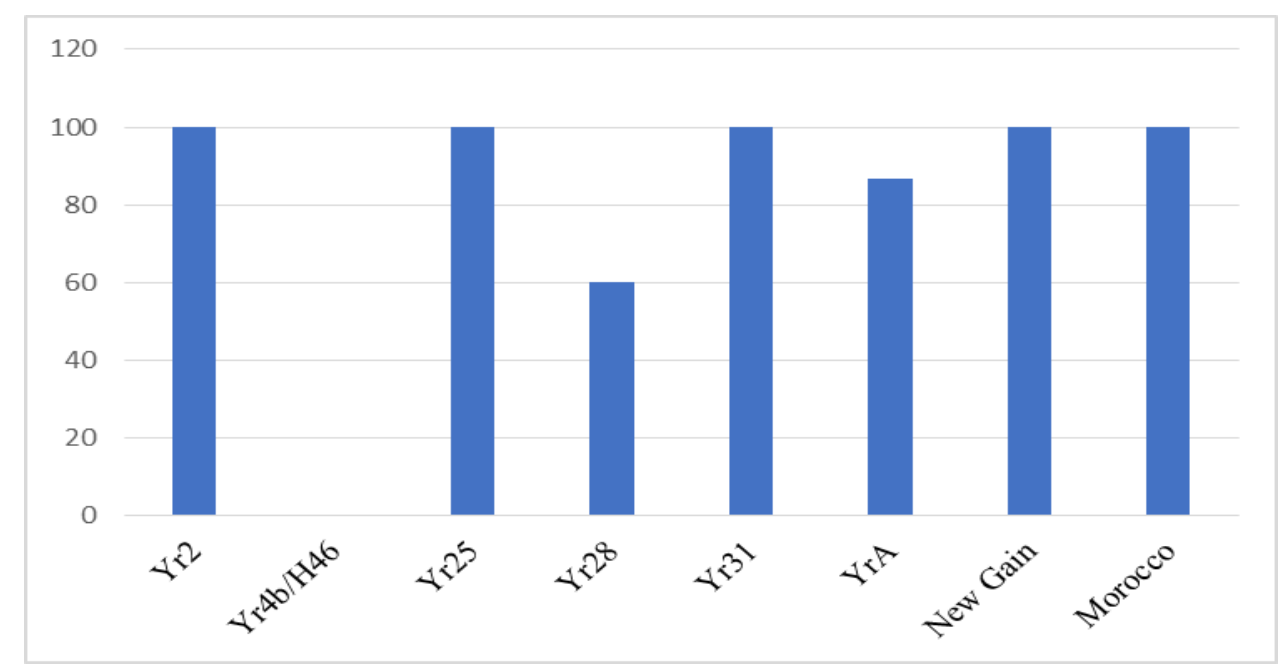

Figure 3. Virulence of stripe rust races against Yr genes (Differential set) 


\section{Conclusion}

These studies were part of the efforts to explore the status of emerging and aggressive races/pathotypes of PST in Pakistan and to check the response of isogenic lines against these races. The data presented here provide essential information required to deploy the resistant gene to confer resistance to breed wheat varieties/cultivars resistant to stripe rust disease.

\section{Authors' contributions}

Conceived and designed the experiments: $\mathrm{M}$ Sufyan \& JI Mirza, Performed the experiments: M Sufyan, JI Mirza \& M Saeed, Analyzed the data: JI Mirza, M Fayyaz \& AR Rattu, Contributed materials/ analysis/ tools: KA Khanzada \& MQ Kakar, Wrote the paper: M Sufyan, JI Mirza \& M Saeed.

\section{References}

1. World Agricultural production. In: Circular Series, WAP 03-19. (United States Department of Agriculture Foreign Agricultural Service, 2019). https://apps.fas.usda.gov/psdonline/circular s/production.pdf

2. Shewry PR \& Hey SJ (2015). The contribution of wheat to human diet and health. Food Energy Security 4: 178-202.

3. United-Nations. World population prospects: The 2015 revision, Key findings and advance tables. (Department of Economic and Social Affairs PD, United Nations, 2015). https://www.un.org/en/development/desa/p ublications/worldpopulation-prospects2015-revision.html

4. Chen W, Wellings C, Chen X, Kang Z \& Liu $\mathrm{T}$ (2014). Wheat stripe (yellow) rust caused by Puccinia striiformis f. sp. Tritici. Mol Plant Pathol 15: 433-446.

5. Solh M, Nazari K, Tadesse W \& Wellings CR (2012). The growing threat of stripe rust worldwide. In: Borlaug Global Rust Initiative, 2012 Technical Workshop, Beijing, China (ed. McIntosh R. A.).

6. Ali S, Rodriguez-Algaba J, Thach $\mathrm{T}$, Sørensen CK, Hansen JG, Lassen P, Nazari K, Hodson DP, Justesen AF, \& Hovmøller
MS (2017). Yellow Rust Epidemics Worldwide Were Caused by Pathogen Races from Divergent Genetic Lineages. Frontiers in Plant Sci 8: 1057.

7. Beddow JM \& Pardey PG (2015). Moving matters: the effect of location on crop production. J Econ. Hist 75: 219-249.

8. Ezzahiri B, Yahyaoui A, Hovmøller MS (2009). An analysis of the 2009 Epidemic of yellow rust on wheat in Morocco, in The 4th Regional Yellow Rust Conference for Central and West Asia and North Africa (Antalya: Turkish Ministry of Agriculture and Rural Affairs, International Center for Agricultural Research in the Dry Areas, International Maize and Wheat Improvement Center, Food and Agriculture Organization of the United Nations.

9. Rahmatov M, Eshonova Z, Ibrogimov A, Otambekova M, Khuseinov B \& Muminjanov H (2012). Monitoring and evaluation of yellow rust for breeding resistant varieties of wheat in Tajikistan.

10. El Amil R (2015). Effet de l'hôte et de la Température sur la Structure de la Population de Puccinia striiformis f. sp. Tritici, Agent de la Rouille Jaune du blé au Moyen Orient. Ph.D., Université Paris-Sud.

11. Justesen AF, Ridoutb CJ, Hovmøller MS (2002). The recent history of Puccinia striiformis f.sp. tritici in Denmark as revealed by disease incidence and AFLP markers. Plant Pathol 51: 13-23.

12. Kolmer JA (2005). Tracking wheat rust on a continental scale. Curr Opi in Plant Biol 8: 441-449.

13. Wellings CR (2007). Puccinia striiformis in Australia: A review of the incursion, evolution and adaptation of stripe rust in the period 1979-2006. Aust J Agric Res 58: 567-575.

14. Hovmoller MS, Yahyaoui AH, Milus EA \& Justesen AF (2008). Rapid global spread of two aggressive strains of a wheat rust fungus. Mol Ecol 17: 3818-3826.

15. Stubbs RW (1985). Stripe rust. In: Roelfs AP, Bushnell WR, editors. The Cereal Rusts, Diseases, Distribution, Epidemiology and Control. London, UK: Academic Press. pp. 61-101. 
16. Chen XM (2005). Epidemiology and control of stripe rust [Puccinia striiformis f. sp. tritici] on wheat. Can J Plant Pathol 27: 314-337.

17. Milus EA, Kristensen K \& Hovmøller MS (2009). Evidence for increased aggressiveness in a recent widespread strain of Puccinia striiformis f.sp. tritici causing stripe rust of wheat. Phytopath 99: 89-94.

18. Singh RP, William HM, Huerta-Espino J \& Rosewarne G (2004). Wheat rust in Asia: meeting the challenges with old and new technologies. In proceedings of the 4th International Crop Science Congress; 26 Sep- 1 Oct 2004; Brisbane, Australia. Available at: http://www.cropscience.org.au/icsc2004/sy mposia/3/ 7/141_singhrp.htm.

19. Afzal SN, Haque MI, Ahmadani MS, Bashir S \& Rehman A (2007). Assessment of yield losses caused by Puccinia striiformis triggering stripe rust in the most common wheat varieties. Pak. J. Bot 39: 2127-2134.

20. Bux H, Ashraf M \& Chen XM (2004). Expression of high temperature adult plant (HTAP) resistance against stripe rust (Puccinia striiformis f. sp. tritici) in Pakistan wheat landraces. Can J Plant Pathol 34: 6874.

21. Thach T, Ali S, Rodriguez-Algaba J, Justesen AF \& Hovmøller MS (2015). Recovery and virulence phenotyping of the historic 'Stubbs collection' of the yellow rust fungus Puccinia striiformis from wheat. Ann Appl Biol 167: 314-326.

22. Hovmoller MS, Rodriguez-Algaba J, Thach T, \& Sørensen C (2017). "Race typing of Puccinia striiformis on wheat," in Methods in Molecular Biology, ed S. Periyannan (New York, NY: Humana Press).

23. Marchal C, Zhang J, Zhang P (2018). BEDdomain-containing immune receptors confer diverse resistance spectra to yellow rust. Nat Plants 4: 662-668.

24. Wan A \& Chen X (2014). Virulence characterization of Puccinia striiformis $\mathrm{f}$. $\mathrm{sp}$. tritici using a new set of Yr single-gene line differentials in the United States in 2010. Plant Dis. 98: 1534-1542.

25. Fayyaz M, Shahzad A, Ali GM, Rattu AR \& Muhammad F (2017). Identification of stripe rust (Puccinia striiformis) resistant genes among Pakistani spring wheat by using molecular markers. Int. J. Biosci 11: 320334.

26. Khan MA \& Mumtaz H (2004). Combining yellow rust resistance with high yield in grain wheat. In Proceedings of the Abstracts, Second Regional Yellow Rust Conference for Central \& West Asia and North Africa, Islamabad, Pakistan, 28: 22-26.

27. Sumaira R, Ahmad I, Kazi AM, Sahi GM, Mirza JI, Rehman A \& Ashraf M (2010). Virulence variation of Puccinia striiformis Westend. f. sp. tritici in Pakistan. Arch Phytopathol 43: 875-882.

28. Wang L, Ma J, Zhou R, Wang X \& Jia J (2002). Molecular tagging of the yellow rust resistance gene Yr10 in common wheat, $\begin{array}{lll}\text { P.I.178383 (Triticum aestivum L.). } & \end{array}$ Euphytica 124: 71-73.

29. Bariana HS, Brown GN, Ahmed NU, Khatkar S, Conner RL, Wellings CR, Halley S, Sharp P \& Laroche A (2002). Charecterization of Tritium vavilovii derived stripe rust resistance using genetic, cytogenetic and molecular analyses and marker assisted selection. Theoretical and Appl Gene 104: 315-320.

30. Ali S, Leconte M, Rahman H, Saqib MS, Gladieux P, Enjalbert J \& de VallavieillePope C (2014). A high virulence and pathotype diversity of Puccinia striiformis f.sp. tritici at its center of diversity, the Himalayan region of Pakistan. Plant Pathol 140: 275-290.

31. Robert O, Abelard C \& Dedryer F (1999). Identification of molecular markers for the detection of the yellow rust resistance gene Yr17. Mol Breeding 5: 167-175. 